\title{
The Production of Alkaline Protease from a Recombinant Strain Expressed Apr
}

\author{
Mei-Shuo ZHANG ${ }^{1, a}$, Ya-Nan YANG ${ }^{1, b}$, Xue-Nan $L^{1, c}$, Song-Yi LIN ${ }^{1, d, *}$ \\ ${ }^{1}$ Laboratory of Nutrition and Functional Food, Jilin University, Changchun, 130062, P. R. China \\ azmeishuo@163.com, b595018213@qq.com, 564796545@qq.com, dinsongyi730@163.com \\ ${ }^{*}$ Corresponding author
}

Keywords: Alkaline Protease, Recombinant, Optimization, Activity.

\begin{abstract}
The alkaline protease gene, Apr, from Bacillus licheniformis 2709 was cloned into an expression vector pET $-28 \mathrm{~b}(+)$. The pET $-28 \mathrm{~b}(+)$ - Apr was expressed in a high expression strain E. coli BL21. In order to develop and optimize mathematical model of protease activity, three variables were investigated, including peptone concentration ( $6 \mathrm{~g} / \mathrm{L}$ to $10 \mathrm{~g} / \mathrm{L})$, incubation time (16 h to $32 \mathrm{~h})$ and agitation frequency $(150 \mathrm{r} / \mathrm{min}$ to $240 \mathrm{r} / \mathrm{min})$, by response surface methodology (RSM). The protease produced by recombinant strain with optimal protease activity was predicted to be obtained at: the peptone concentration $8.08 \mathrm{~g} / \mathrm{L}$, the incubation time $24.25 \mathrm{~h}$ and the agitation frequency 180.14 $\mathrm{r} / \mathrm{min}$. Under the optimal condition, the protease activity achieved $1125.81 \mathrm{U} / \mathrm{mL}$.
\end{abstract}

\section{Introduction}

B. licheniformis strains are listed in the third edition of Food Chemicals Codex (1981) as sources of carbohydrase and protease enzyme preparations used in food processing [1]. With a diverse range of protease enzyme applications, in the food industry, alkaline protease should be produced commercially in high yields utilizing a low cost method. Protease production is an inherent capacity of all microorganisms, however only those microbes that produce substantial amounts of extracellular enzyme are of industrial importance. Extracellular protease production in microorganisms is highly influenced by media components, viz. variation in carbon/nitrogen ratio, presence of some easily metabolizable sugars, such as glucose [2] and presence of metal ions [3]. In addition to these, several other factors such as aeration, inoculum density, $\mathrm{pH}$, temperature, and incubation time also affect the amount of extracellular protease produced [4,5]. Glucose and peptone were found to be important factors in enhancing the formation of alkaline protease. Statistical modelling approaches offer ideal ways for process optimization studies in biotechnology where many variables may be interacting [6].

\section{Materials and Methods}

\section{Construction of Recombinant Strain}

The B. Licheniformis 2709 protease gene Apr sequence was based on EMBL and DDBJ. The Apr gene was obtained by SOE-PCR in a Thermal Cycler (Thermo Electron Corporation, Milford, MA, USA) with the thermal program of 1 cycle of $94{ }^{\circ} \mathrm{C}$ for $2 \mathrm{~min}, 30$ cycles of $94{ }^{\circ} \mathrm{C}$ for $30 \mathrm{~s}, 60{ }^{\circ} \mathrm{C}$ for 30 $\mathrm{s}, 72{ }^{\circ} \mathrm{C}$ for $1.1 \mathrm{~min}$, and 1 cycle of $72{ }^{\circ} \mathrm{C}$ for $7 \mathrm{~min}$. The forward primer sequence was 5'-GGATCTAACGCGATACGC-3'. The reverse primer sequence was 5'-CTCGAGCCGGAAATACTT-3'. The Apr gene was inserted into the corresponding sites of vector $\mathrm{pET}-28 \mathrm{~b}(+)$ to obtain the recombinant expression vector $\mathrm{pET}-28 \mathrm{~b}(+)$-Apr. The constructed vector was transformed to competent cells of E. coli BL 21. After a verification of its presence by digestion of XhoI and NcoI, sodium salt-polyacrylamide gel electrophoresis (SDS-PAGE) was run on a Mini Protean 4 gel system. The recombinant strain was prepared according to previous study [7]. 


\section{Experimental Design}

Five milliliters of 24-hour-old inoculum of recombinant strain was added to $95 \mathrm{~mL}$ production medium in $250 \mathrm{~mL}$ Erlenmeyer flasks. The composition of production medium comprised: glucose (8 $\mathrm{g} / \mathrm{L}$ ), peptone (variable) and salt solution $\left(30 \mathrm{~mL}\right.$, salt solution containing $\mathrm{KH}_{2} \mathrm{PO}_{4} 5 \mathrm{~g} / \mathrm{L}$, $\mathrm{MgSO}_{4} \cdot 7 \mathrm{H}_{2} \mathrm{O} 2 \mathrm{~g} / \mathrm{L}$ and $\mathrm{FeSO}_{4} \cdot 7 \mathrm{H}_{2} \mathrm{O}, 0.1 \mathrm{~g} / \mathrm{L}$ ). The incubation time and agitation were observed in the study. The $\mathrm{pH}$ value of the Inoculum was adjusted to $\mathrm{pH} 7.0 \pm 0.05$ by adding $1 \mathrm{~N} \mathrm{NaOH}$ or $1 \mathrm{~N}$ $\mathrm{HCl}$. Recombinant strain and mycelidium were induced with $1 \mathrm{mM}$ isopropyl- $\beta$-d-thiogalactopyranoside (IPTG) and cultivated for additional $5 \mathrm{~h}$. These three independent variables were the peptone concentration $(\mathrm{g} / \mathrm{L})$, incubation time $(\mathrm{h})$ and agitation frequency ( $\mathrm{r} / \mathrm{min})$.

\section{Determination of Protease Activity}

Protease activity was measured by the method described by Kembhavi et al. [8] using casein as a substrate. One percent of casein substrate was prepared in $0.1 \mathrm{M}$ sodium carbonate buffer at $\mathrm{pH}$ 9.7. The reaction mixture consisting of $1 \mathrm{~mL}$ of $100 \mu \mathrm{g} / \mathrm{mL}$ casein and $1 \mathrm{~mL}$ of diluted enzyme was incubated for $20 \mathrm{~min}$ at $40{ }^{\circ} \mathrm{C}$ and then terminated with $2 \mathrm{~mL}$ of $5 \%$ trichloroacetic acid (TCA). The absorbance of filtrate by $0.22 \mu \mathrm{m}$ filter membrane was measured at $280 \mathrm{~nm}$. Parallel blanks were run with each sample. In one unit of protease activity was defined as the amount of enzyme required to liberate $1 \mu \mathrm{g}$ of tyrosine per minute under the used experimental conditions. All experiment represented the mean of at three determinations carried out in duplicate.

\section{Results and Analysis}

The RSM was used to optimize experimental parameters including peptone concentration $(6 \mathrm{~g} / \mathrm{L}$ to $10 \mathrm{~g} / \mathrm{L})$, incubation time $(16 \mathrm{~h}$ to $32 \mathrm{~h})$ and agitation frequency $(150 \mathrm{r} / \mathrm{min}$ to $210 \mathrm{r} / \mathrm{min})$. The experimental dates were shown in Table 1. By applying multiple regression analyses on the experimental data, the final mathematical model could be expressed by the following second-order polynomial equation:

$$
\begin{aligned}
& Y=1125.64198+4.30556 X_{1}+5.64815 X_{2}+1.74383 X_{3}-0.21605 X_{1} X_{2}-23.20988 X_{1} X_{3} \\
& +0.030864 X_{2} X_{3}-54.47531 X_{1}{ }^{2}-93.02469 X_{2}{ }^{2}-97.31481 X_{3}^{2} .
\end{aligned}
$$

Where, $\mathrm{Y}$ is the protease activity of recombinant strain $(\mathrm{U} / \mathrm{mL}) ; \mathrm{X} 1$ is the peptone concentration $(\mathrm{g} / \mathrm{L}) ; \mathrm{X} 2$ is the incubation time $(\mathrm{h}) ; \mathrm{X} 3$ is the agitation frequency $(\mathrm{r} / \mathrm{min})$. The predicted values based on the quadratic predictive model were calculated, as shown in Table 1 . The regression model was tested by ANOVA, as shown in Table 2. Lack of fit could be used to judge the validity of the model and the P-value was used to check the significance of the model . It could be seen that the lack of fit value of the mathematical model was 0.3203 and the $\mathrm{P}$-value of the model was significant $(\mathrm{P}<0.05)$, which indicated that the model appropriately fits. The coefficient $\left(\mathrm{R}^{2}\right)$ was 0.8994 , which was defined to explain the fitness of the regression models. The smaller the value of $\mathrm{R}^{2}$, the worse relevant was the dependent variables in the model. In this study, it indicated a high degree correlation between the observed and the predicted values. The statistical analysis showed that the regression model could significantly $(\mathrm{P}<0.05)$ model the experimental results and the predicted results were very close to the observed experimental responses. Therefore, the model of the protease activity could be used to analyze and predict the effect of the independent variables on the protease activity.

Based on the analysis of validity for the variables, the variables $\left(\mathrm{X}_{1}{ }^{2}, \mathrm{X}_{2}{ }^{2}, \mathrm{X}_{3}{ }^{2}\right)$ were found to have remarkable effects on the protease activity $(P<0.05)$, while the other coefficients $\left(X_{1}, X_{2}, X_{3}, X_{1} \times X_{2}\right.$, $\left.\mathrm{X}_{1} \times \mathrm{X}_{3}, \mathrm{X}_{2} \times \mathrm{X}_{3}\right)$ were not significantly influential $(\mathrm{P}>0.05)$. To show the interactions between the variables and the relationship between responses and experiment levels of each variable, the 2-D contour plots were profiled in Fig. 1. The contour plots at the bottom of the response surface presenting as an ellipse means the interaction effect was significant. The quadratic equation exhibited 
a great accuracy on predicting the protease activity levels. By analyzing the plots, the predicted values for the optimal conditions of protease activity: the peptone concentration $8.08 \mathrm{~g} / \mathrm{L}$, the incubation time $24.25 \mathrm{~h}$, the agitation frequency $180.14 \mathrm{r} / \mathrm{min}$. Under this condition, the protease activity achieves $1125.81 \mathrm{U} / \mathrm{mL}$.

Tab. 1 Box-Benken design matrix and response values for the protease activity of recombinant strain

\begin{tabular}{cccccc}
\hline No. & $\mathrm{x}_{1}$ & $\mathrm{x}_{2}$ & $\mathrm{x}_{3}$ & Experimental Y $(\mathrm{U} / \mathrm{mL})$ & Predicted $\mathrm{Y}(\mathrm{U} / \mathrm{mL})$ \\
\hline 1 & -1 & 0 & 1 & $986.75 \pm 2.52$ & 994.50 \\
2 & -1 & 0 & -1 & $940.21 \pm 7.60$ & 944.59 \\
3 & 1 & 1 & 0 & $996.51 \pm 7.19$ & 987.88 \\
4 & -1 & -1 & 0 & $959.35 \pm 5.56$ & 967.97 \\
5 & 0 & 1 & -1 & $922.80 \pm 3.60$ & 939.18 \\
6 & 1 & 0 & -1 & $1007.37 \pm 6.43$ & 999.62 \\
7 & 0 & 0 & 0 & $1135.64 \pm 5.81$ & 1125.64 \\
8 & 0 & 1 & 1 & $929.72 \pm 11.44$ & 942.73 \\
9 & 1 & -1 & 0 & $956.26 \pm 7.40$ & 977.02 \\
10 & 1 & 0 & 1 & $961.07 \pm 10.91$ & 956.69 \\
11 & 0 & 0 & 0 & $1105.64 \pm 9.64$ & 1125.64 \\
12 & 0 & 0 & 0 & $1135.64 \pm 5.81$ & 9725.64 \\
13 & -1 & 1 & 0 & $1000.46 \pm 10.11$ & 931.37 \\
14 & 0 & -1 & 1 & $947.74 \pm 9.58$ & 927.94 \\
15 & 0 & -1 & -1 & $940.95 \pm 12.25$ & \\
\hline
\end{tabular}

Tab. 2 Design matrix evaluation for the response surface quadratic model

\begin{tabular}{lllllll}
\hline Source & $\begin{array}{l}\text { Coefficien } \\
\text { t estimate }\end{array}$ & $\begin{array}{l}\text { Standard } \\
\text { Error }\end{array}$ & $\begin{array}{l}\text { Sum of } \\
\text { Squares }\end{array}$ & $\begin{array}{l}\text { Mean } \\
\text { Square }\end{array}$ & F-Value & $\begin{array}{l}\text { p-value } \\
\text { Prob > F }\end{array}$ \\
\hline Model & & & 70965.65 & 7885.07 & 14.914 & 0.0042 \\
Intercept & 1125.64 & 13.28 & & & & \\
$\mathrm{X}_{1}$ & 4.31 & 8.13 & 148.30 & 148.30 & 0.28 & 0.6190 \\
$\mathrm{X}_{2}$ & 5.65 & 8.13 & 255.21 & 255.21 & 0.48 & 0.5182 \\
$\mathrm{X}_{3}$ & 1.74 & 8.13 & 24.33 & 24.33 & 0.05 & 0.8386 \\
$\mathrm{X}_{1} \times \mathrm{X}_{2}$ & -0.22 & 11.50 & 0.19 & 0.19 & $<0.001$ & 0.9857 \\
$\mathrm{X}_{1} \times \mathrm{X}_{3}$ & -23.21 & 11.50 & 2154.79 & 2154.79 & 4.08 & 0.0995 \\
$\mathrm{X}_{2} \times \mathrm{X}_{3}$ & 0.03 & 11.50 & $<0.005$ & $<0.005$ & $<0.001$ & 0.9980 \\
$\mathrm{X}_{1}{ }^{2}$ & -54.48 & 11.97 & 10957.14 & 10957.14 & 20.72 & 0.0061 \\
$\mathrm{X}_{2}{ }^{2}$ & -93.02 & 11.97 & 31951.73 & 31951.73 & 60.43 & 0.0006 \\
$\mathrm{X}_{3}{ }^{2}$ & -97.31 & 11.97 & 34966.79 & 34966.79 & 66.14 & 0.0005 \\
Residual & & & 2643.58 & 528.72 & & \\
Lack of Fit & & & 2043.58 & 681.19 & 2.27 & 0.3203 \\
Pure Error & & & 600 & 300 & & \\
Core Total & & & 73609.23 & & & \\
\hline
\end{tabular}

The protease activity in samples is shown as a functional interaction between either peptone concentration and incubation time (A) or peptone concentration and agitation frequency (B) or incubation time and agitation frequency $(\mathrm{C})$. 
(A)
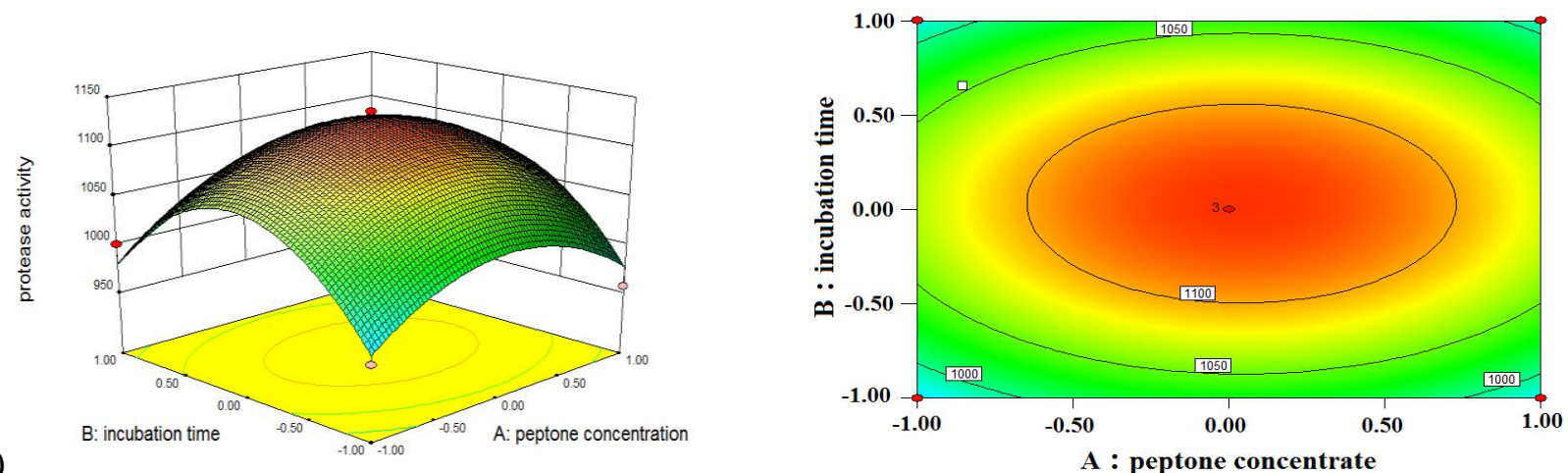

(B)
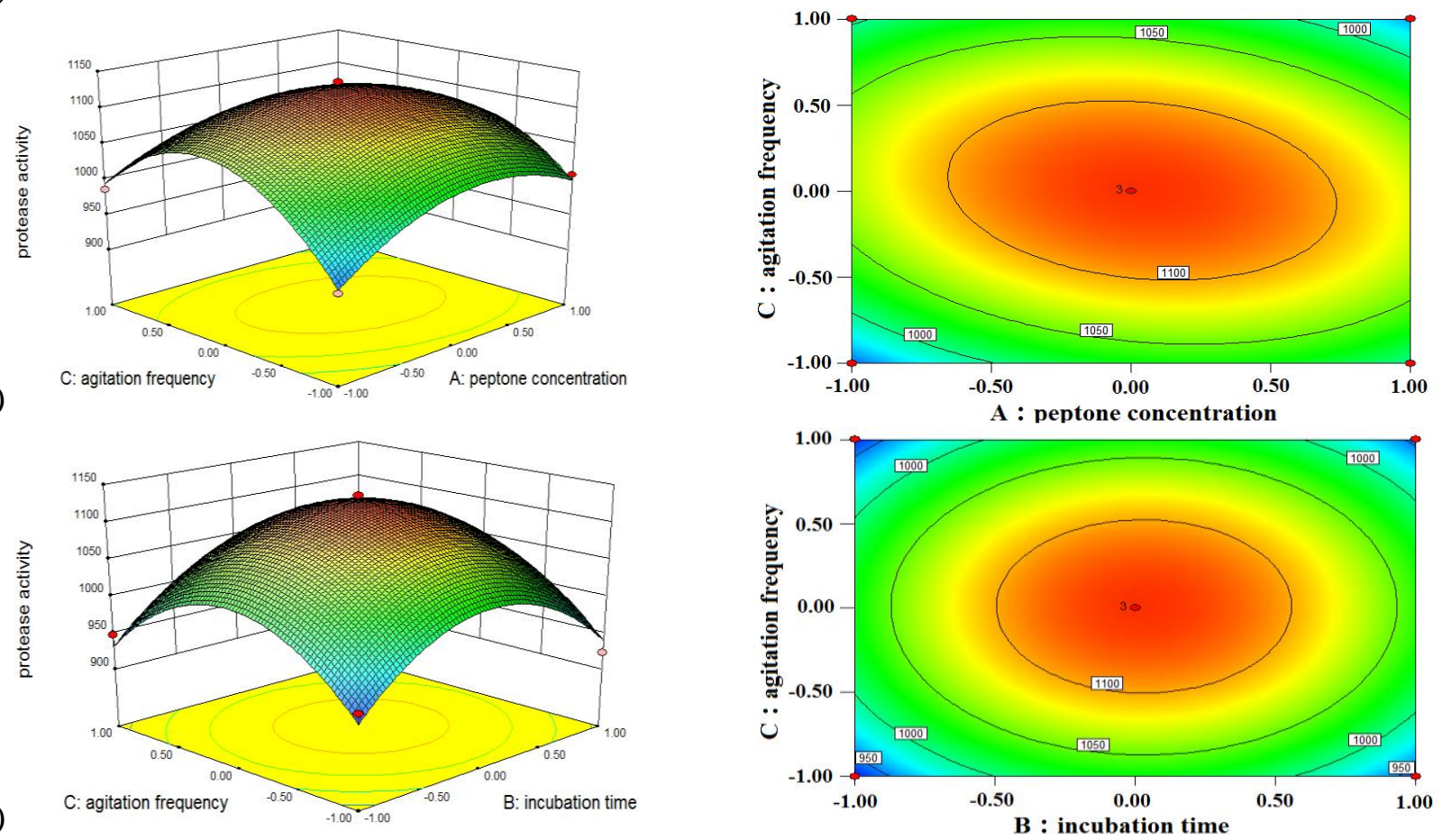

Fig. 1 Response surface plots of decrease of protease activity of recombinant strain

\section{Summary}

The alkaline protease gene, Apr, from Bacillus licheniformis 2709 was cloned into an expression vector $\mathrm{pET}-28 \mathrm{~b}(+)$. The $\mathrm{pET}-28 \mathrm{~b}(+)$ - Apr was expressed in a high expression strain E. coli BL21. The recombinant strain was prepared according to previous study. The predicted values for the optimal conditions of protease activity: the peptone concentration $8.08 \mathrm{~g} / \mathrm{L}$, the incubation time 24.25 $\mathrm{h}$, the agitation frequency $180.14 \mathrm{r} / \mathrm{min}$, the protease activity achieved $1125.81 \mathrm{U} / \mathrm{mL}$.

\section{Acknowledgement}

The authors acknowledge the financial support provided by the Key Projects in the National Science \& Technology Pillar Program during the Twelfth Five-Year Plan Period (2012BAD33B03) and the Youth Scientific Innovation Leading Talent and Team Building Project of Jilin Province (20140519014JH).

\section{References}

[1] A.S. de Boer, F. Priest, B. Diderichsen: Appl Microbiol Biot. Vol. 40 (1994) 595-598.

[2] M.A. Ferrero, G.R. Cartro, C.M. Abate, M.D. Baigori, F. Sineriz: Appl Microbiol Biotechnol. Vol. 45 (1996) 327-332. 
[3] R H. Varela, M.D. Ferrari, L. Belobradjic, R. Weyrauch, M.L. Loperena: World J Microbiol Biotechnol. Vol. 12 (1996) 643-645.

[4] A. Hameed, T. Keshavarz, C.S. Evans: J Chem Technol Biotechnol. Vol. 74 (1999) 5-8.

[5] P.N. Nehete, Shah VD, R.M. Kothari: Biotechnol Lett. Vol. 7 (1985) 413-418.

[6] P.D. Haaland Statistical problem solving. In: Haaland PD, editor. Experimental Design in Biotechnology. New York: Marcel Dekker, Inc, (1989).

[7] S.Y. Lin, M.S. Zhang, J.B. Liu, and G.S. Jones: J Biosci and Bioeng. Vol. 119 (2015) 284-288.

[8] A.A. Kembhavi, A. Kulharni, A.A. Pant: Appl Biochem Biotechnol. Vol. 38 (1993) 83-92. 